\title{
A localização da produção silvícola no estado do Paraná
}

Jandir Ferrera de Lima*

\begin{abstract}
Resumo
Esse artigo analisa o deslocamento da produção silvícola e seu padrão de localização entre as microrregiões do Paraná no Brasil. O procedimento metodológico consistiu na estimativa dos indicadores de localização e o efeito competitivo a partir de dados do valor da produção silvícola regional do Estado do Paraná. A periodização utilizada foi o comparativo entre 2005 e 2016. Os principais resultados apontaram para um ganho significativo de competitividade e acréscimo de produção nas microrregiões de Jaguariaíva, Cerro Azul, Telêmaco Borba, União da Vitória e Ibaiti. A atividade de madeira para papel e celulose teve uma expansão importante, enquanto a produção de carvão vegetal se reduziu nas regiões paranaenses.
\end{abstract}

Palavras-chave: Economia florestal. Desenvolvimento regional. Economia regional. Economia paranaense. Competitividade.

\section{The location of forestry production in the Paraná state in Brasil}

\begin{abstract}
This paper analyzes the displacement of forestry production and its location pattern among the regions of the Paraná State in Brazil. The methodological procedure consisted of the estimation of localization and the competitive effect indicators calculated from data on the value of regional forestry production in the Paraná State. The periodization used was the comparison between 2005 and 2016. The main results pointed to a significant gain in competitiveness and increase of production in the regions of Jaguariaíva, Cerro Azul, Telêmaco Borba, União da Vitória and Ibaiti. The activity of wood for pulp and paper had an important expansion, while the production of charcoal was reduced in the Paraná State regions.
\end{abstract}

Keywords: Regional development. Forest economics. Regional economy. Paraná State economy. Competitiveness.

\section{Introdução}

A economia de base florestal é um dos ramos de atividade mais pujantes na economia paranaense. Praticamente $25 \%$ das terras do Paraná são dedicadas a atividades ligadas a floresta e seus subprodutos, que vão desde a extração de erva mate, resinas e óleos essenciais até a obtenção de madeira para processamento industrial e combustível (IPARDES, 2018).

Já no início dos anos 1970, Zaniolo (1970) apontava que o planejamento global do setor florestal demandava a análise potencial de localização econômica de reflorestamentos, apontando assim as condições de produção das regiões do Estado do Paraná. Isso poderia fortalecer as políticas de fomento para o setor e a seleção de regiões prioritárias para as políticas de desenvolvimento florestal. Lembrando que o modelo econômico a ser adotado na economia florestal é aquele cujo princípio se baseia no rendimento sustentável, ou seja, não cause

\footnotetext{
* Doutorado em Desenvolvimento Regional (UQAC/Canadá). Professor do Programa de Pós-Graduação em Desenvolvimento Regional e Agronegócios (UNIOESTE/Toledo-PR), http://orcid.org/0000-0002-0359-0670 E-mail: jandir.lima@unioeste.br
} 
deseconomias na produção futura, garanta o suprimento de matéria-prima e estimule a localização de negócios florestais no entorno das áreas de produção.

Ainda nos anos 1970, estudo de Guimarães (1974) já apontava a necessidade de mais pesquisas e desenvolvimento de tecnologias para o setor madeireiro. Além disso, criar uma sistemática para a melhor regulamentar o setor tanto no Brasil quanto no Paraná eram exigências para se avançar na expansão do comercio exterior, cujas exportações em 1972 totalizaram 476 $\mathrm{mil} / \mathrm{m}^{3}$, ou seja, $80 \%$ das exportações brasileiras no período.

A partir do zoneamento econômico ecológico florestal, em 1971 se definiram as áreas prioritárias para o reflorestamento, visando tanto a conservação do solo como o regime de águas e as necessidades futuras da industrialização da madeira. Apesar do zoneamento de produção, no final da década de 1970 e início dos anos 1980, a necessidade de novas políticas de incentivos fiscais, a ampliação da área utilizada para atender a demanda industrial de 60 mil hectares na época e a definição de créditos a logo prazo se impuseram para manter a oferta de matéria prima e o potencial do Estado em termos de reflorestamento e da expansão do setor industrial madeireiro (ALMEIDA; MACDONELL, 1976; LOURENÇO, 1979).

Nos anos 1970 e 1980, as regiões Oeste, Sudoeste e Centro Sul do Paraná eram as grandes fornecedoras de matérias primas para a fabricação de compensados e outros derivados de madeira. Nessa época também já se vislumbrava uma oferta nativa de matéria prima para um horizonte de 20 anos, ou seja, até o início do século XXI (BERGER; ALMEIDA, 1972). Com o fechamento da fronteira agrícola e o advento da nova Constituição Federal de 1988, a produção de madeira e seus derivados sofreram novas regulamentações e as regiões tradicionais do Paraná, na produção florestal, deram lugar a novos tipos de exploração e a novos perfis de produção silvícola.

No final dos anos 1980 e na primeira metade dos anos 1990, com a crise econômica e fiscal que atingiu os estados brasileiros e a mudança na matriz econômica do Estado do Paraná avançando rumo a agroindustrialização e na formação de um complexo metal mecânico, a expansão do setor madeireiro em termos de área de exploração ficou mais restrita. A retomada da indústria paranaense no final dos anos 1990, com a presença de indústrias de mais alta tecnologia e o declínio das atividades tradicionais, como a madeireira e cafeeira, marcou o avanço das atividades de maior conteúdo tecnológico e a especialização nos grupos tecnológicos e fornecedor, estimulando o declínio da base produtiva que foi importante nos anos 1970 e 1980, 
no caso a silvícola (NOJIMA, 2002). Mesmo assim há um espaço significativo de crescimento de crescimento da economia florestal.

Atualmente, há uma crescente demanda por serviços e produtos florestais em escala mundial. Isso significa novas oportunidades econômicas na exploração de produtos ligados a cadeia produtiva florestal, tanto para exportação quanto para importação. E, no caso das importações, elas abrem um leque de oportunidades para se substituir matéria prima e produtos florestais importados por similares nacionais (MAXIR; MASULLO, 2017). Frente ao exposto, esse artigo analisa o deslocamento da produção silvícola e seu padrão de localização entre as microrregiões do Paraná no início do século XXI.

\section{A silvicultura e o desenvolvimento regional}

As atividades ligadas à silvicultura compreendem o florestamento e o reflorestamento. Na sua cadeia produtiva se inserem o beneficiamento da madeira e seus produtos derivados e demais produtos como essências, fibras, folhas e resinas. No Brasil, a silvicultura responde por $100 \%$ do suprimento de matéria prima para a indústria de celulose e painéis e $70 \%$ da indústria de compensados (FISCHER, 2009). Ou seja, ela é um ramo de atividade econômica que se insere na dinâmica de regiões periféricas, em especial aquelas produtoras de matéria-prima e de atividades ligadas à indústria da madeira e do mobiliário.

A interligação dos elos da cadeia produtiva das atividades silvícolas formam arranjos organizacionais, que vão desde a formação de contratos futuros para a compra de matéria-prima até a demanda presente, com o fornecimento próprio ou de terceiros dos produtos e subprodutos das florestas. E a estrutura de plantação, gerenciamento ou exploração de florestas plantadas ou nativas envolvem desde arrendamentos, parcerias, atividades de fomento e cooperação técnica (FISCHER, 2009).

Outro elemento importante na exploração silvícola, além dos arranjos organizacionais da cadeia produtiva, é a atenção com aspectos ambientais. Nesse sentido, para minimizar danos ambientais e o impacto nos recursos naturais, a cadeia produtiva silvícola avança em práticas mecânicas destinadas à preservação do solo, em especial no momento da destoca ou readequação do terreno para a prática agropecuária. A silvicultura também serve como atividade para as áreas degradadas. Em algumas regiões, a silvicultura ocupa áreas degradadas ou sem condições para a produção agropecuária, com o intuito de reaproveitá-las, recuperá-las e 
gerarem um uso econômico promovendo o desenvolvimento regional. A recuperação da flora em áreas degradadas auxilia na recomposição da fauna, principalmente quando o reflorestamento se dá com espécies nativas. Sem contar que a formação de matéria orgânica também estimula a formação de micro-organismos no solo recuperando a fertilidade (SANTOS; SILVA, 2013). Ou seja, o uso da silvicultura em algumas regiões é mais que uma atividade econômica, mas um instrumento de recuperação de capacidade produtiva.

Os impactos ambientais da exploração da madeira são passiveis de medidas corretivas, que vão desde o planejamento de exploração de determinadas áreas sempre conservando as áreas próximas e no entorno de cursos d'água ou nascentes; o terraceamento, cerceamento e a construção de curvas de nível e barreiras antierosivas; a inserção das melhores práticas de manejo e extração preservando o solo e suas características físico-químicas; adequar a exploração silvícola conforme as diretrizes dos processos de certificação; reaproveitar áreas degradadas ou sem uso agropecuário, etc... (SANTOS; SILVA, 2013).

Esses procedimentos demonstram que a cadeia produtiva ligada à silvicultura vai além da exploração de florestas, transformação e transporte de madeira, mas envolve o suporte técnico de profissionais de diferentes áreas para minimizar os impactos ambientais. Com isso, a cadeia produtiva da silvicultura se alinha na formação de arranjos produtivos locais (APL), ou seja, aglomerações industriais que exploram uma atividade produtiva convergente e apresentam vantagens competitivas por estarem aglomeradas.

Para Caravieri et al (2014), a formação de APLs geram uma serie de encadeamentos Inter setoriais, tanto do lado do fornecimento de insumos até a aquisição de matérias primas e contratação de serviços conexos aos segmentos produtivos. Além disso, há o caráter inovativo, pois estruturas de exploração e transformação silvícola, que num ambiente de competição e cooperação agregam mais complexidade ao processo produtivo, tendem a estimular mais relações produtivas entre os diferentes elos da cadeia e galgam mais mercados. Isso torna sua localização mais atrativa a empresas ligadas a mesma linha de produção, o que fortalece cada vez mais a aglomeração de empresas.

Outro fator importante ligado ao setor madeireiro e a exploração silvícola é o perfil do capital humano. As atividades da cadeia produtiva da silvicultura tendem a alocar e atrair força de trabalho de baixa qualificação profissional. Com isso, o desenvolvimento e a difusão das atividades produtivas mais adensadas em capital tecnológico para as regiões especializadas na silvicultura encontram uma barreira em termos de competitividade (RAIHER, 2011). Para 
contornar essa barreira, a expansão da cadeia produtiva silvícola deve acompanhar a qualificação e capacitação profissional da população economicamente ativa. A expansão da silvicultura aliada ao fortalecimento do capital humano tende a deixar as regiões mais competitivas e fortalecer sua atratividade locacional para outas atividades produtivas.

Nesse sentido, estudos da localização demonstram a tendência ao adensamento de industriais tradicionais (mobiliário, artefatos de madeira) e não tradicionais (celulose e papel, compensados) em regiões com baixa produtividade agropecuária. Ou seja, a indústria silvícola torna-se um instrumento de ocupação de mão-de-obra em regiões cujas atividades primárias não oferecem alternativas viáveis de exploração e transformação agropecuária. Por isso, os encadeamentos que a extração e transformação silvícola oferecem aliada ao fortalecimento do capital humano se tornam um instrumento de desenvolvimento regional em muitos lugares do Brasil (SOUZA; ALVES, 2011). A sua localização oferecem instrumentos que vão além do planejamento municipal, mas oferecem informações para as políticas públicas de planejamento regional.

\section{Procedimentos metodológicos}

A variável utilizada nesse estudo foi o valor da produção silvícola em reais (R\$) deflacionados pelo Índice Nacional de Preços ao Consumidor (INPC). A produção silvícola total foi dividida nos diferentes ramos produtivos ou subprodutos explorados no Estado do Paraná, quais sejam: carvão vegetal, Eucalipto folhas, lenha, madeira em tora, madeira para papel e celulose, madeira para outras finalidades (compensados, maravalha, serragem, aglomerados) e resinas. A madeira em toras em geral é utilizada como fonte de energia industrial, ou produção de taboas e estaqueamento na construção civil, entre outras utilidades. O que difere do carvão que é utilizado exclusivamente como fonte de energia, tanto em restaurantes, residências quanto para fins industriais. No caso do carvão quanto das toras, o tipo de madeira (Pinus, Eucalipto, Acácia...) foi indiferente, pois nesse estudo se considerou a produção em função da sua utilidade final. Outro exemplo é o caso das resinas, que no Paraná se dá tanto do Eucalipto quanto do Pinus. Em outras regiões do Brasil se explora a Seringueira, entre outros vegetais. Por isso, somente a folha de Eucalipto, que tem uso mais especifico por conta da sua utilidade na indústria farmacêutica e nos produtos de limpeza, teve especificação da espécie. Somente foram considerados os produtos obtidos pela produção de madeira nas áreas cultivadas, destinada para 
fins comerciais ou industriais. Outros usos extraídos diretamente da natureza não foram considerados, bem como aqueles usos com valor bruto de produção inferior a R\$ 1 milhão nos dois períodos da análise.

Os dados do valor bruto da produção silvícola foram coletados junto ao Banco de Dados Estadual (BDE) do Instituto Paranaense de Desenvolvimento Econômico e Social (IPARDES) referenciados em Paraná (2020). A periodização utilizada foi o comparativo entre 2005 e 2016, haja vista a disponibilidade dos dados. Como a produção silvícola depende de áreas abertas, terras disponíveis e rentabilidade, a divisão regional escolhida para atender ao objetivo dessa análise foi a da microrregião, conforme exposto na figura 1.

Figura 1: Microrregiões do Estado do Paraná - 2020.

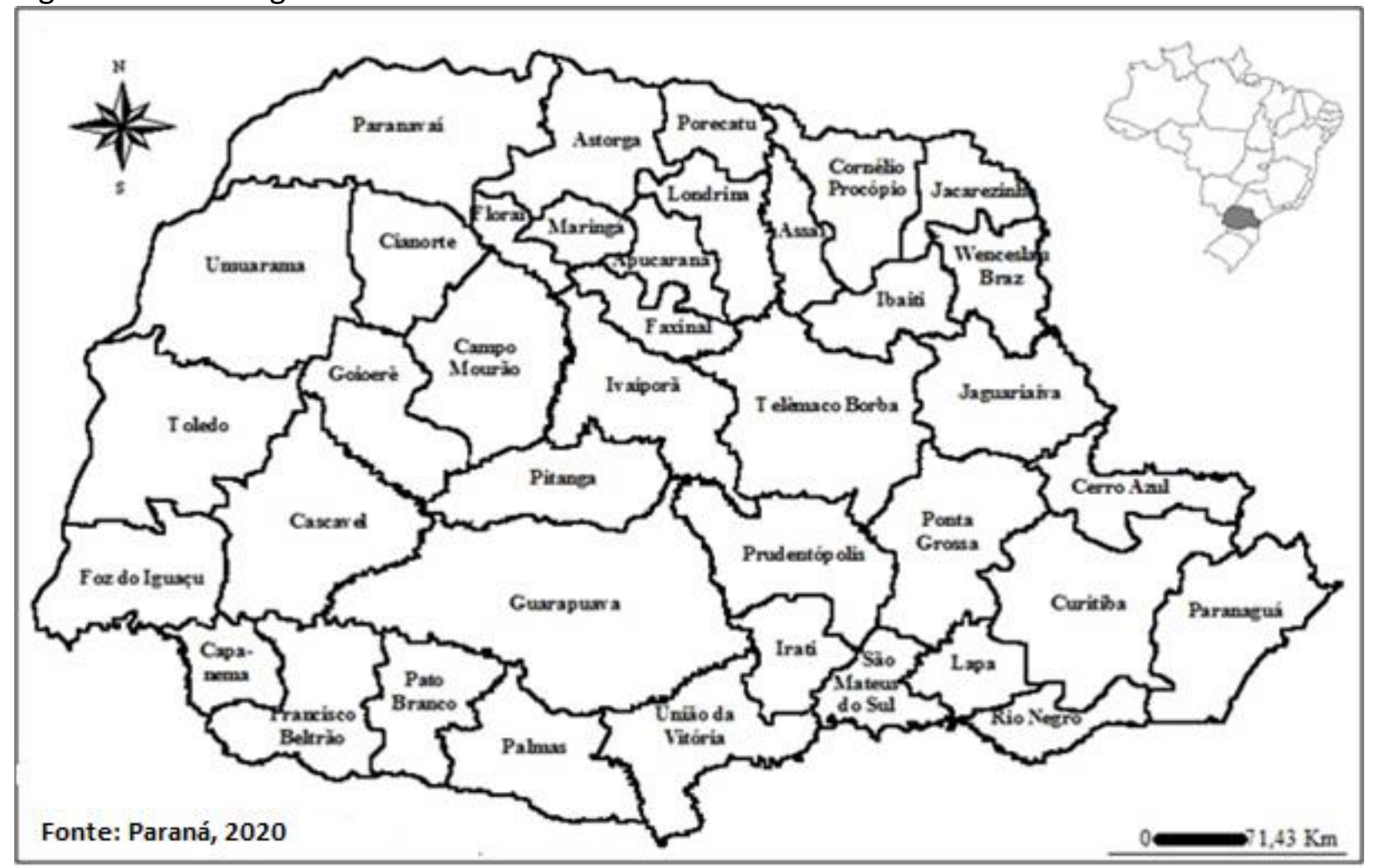

Fonte: Paraná (2020)

Para definir o padrão de localização da produção silvícola e seu deslocamento entre as regiões paranaenses, esse estudo se baseou nos textos clássicos de Haddad (1989), Costa (2002), Ferrera de Lima (2006), Souza e Alves (2011) e Alves (2012). No caso, a produção silvícola em seus diferentes ramos produtivos pode ser definida como $\mathrm{S}$, sendo $S_{i j}$, a produção silvícola no ramo ou especialização "i" na microrregião "j". Assim, para se relacionar a distribuição percentual de S de forma a se captar um padrão de concentração locacional ou de deslocalização de 
produção ao longo do tempo, deve-se tomar $S_{\mathrm{ij}}$ em períodos distintos estimando um indicador de deslocamento ou deslocalização, no caso Idd, sendo:

$$
I d d=\sum_{j}\left[\left|S_{i j}^{A 0} \div \sum_{j} S_{i j}-S_{i j}^{A 1} \div \sum_{j} S_{i j}\right|\right] \div 2
$$

Em que, $A_{\circ}$ é o período inicial de análise, no caso o ano 2005, e $A_{1}$ o período final de analise, no caso o ano de 2016; sendo $S_{i j}$, a produção silvícola no ramo ou especialização "i" na microrregião "j". No caso, as variações do Idd ocorrem entre zero e um, na qual a maior proximidade da unidade (1) reflete um deslocamento de produção mais significativo. A partir do Idd também se pode estimar a reestruturação produtiva, pois o Idd observa o deslocamento espacial das atividades entre as regiões, mas o Indicador de reestruturação (Ireest) indica as mudanças na estrutura produtiva intrarregional, o que leva a uma maior ou menor especialização produtiva. Ou seja, enquanto o indicador de deslocamento foca na redistribuição das atividades produtivas entre as microrregiões, o indicador de reestruturação analisa a composição setorial da economia florestal da região apontando mudanças nessa estrutura que conduziram a uma maior ou menor especialização. A equação 02 apresenta a forma de estimativa do Ireest:

$$
\text { Ireest }=\sum_{i}\left[\left|S_{i j}^{A 1} \div \sum_{i} S_{i j}-S_{i j}^{A 0} \div \sum_{i} S_{i j}\right|\right] \div 2
$$

O Ireest varia entre zero e um. No caso, mais próximo da unidade (1) ocorreu uma reestruturação significativa na especialização produtiva intrarregional. Ao contrário, mais próximo a 0 (zero), a reestruturação foi pouco significativa.

A partir do desdobramento das equações 01 e 02 se observa o Efeito Competitivo (EC) da produção S, sendo:

$$
E C=\sum S_{i j}^{A o}\left[\left(S_{i j}^{A 1} \div S_{i k}^{A o}\right)-\left(\sum_{j} S_{i j}^{A 1} \div \sum_{j} S_{i j}^{A o}\right)\right]
$$

Em que, $A_{o}$ é o período inicial de análise, no caso o ano 2005 , e $A_{1}$ o período final de analise, no caso o ano de 2016; sendo $S_{i j}$, a produção silvícola no ramo ou especialização "i" na microrregião "j".

O Efeito Competitivo (EC) descreve o crescimento da produção silvícola da microrregião analisando sua estrutura produtiva e identificando os componentes dessa estrutura que foram 
os responsáveis para o crescimento do conjunto do setor produtivo. Por isso, seus resultados são positivos (+) ou negativos (-) demonstrando o acréscimo ou perda de produção no período. Para fins de análise serão considerados os ganhos ou perdas superiores a R\$1 milhão. As regiões com sinais positivos significativos conseguiram auferir maiores ganhos de produção, fazendo com que o indicador de EC demonstre como a competitividade do setor se distribuiu no espaço geográfico.

Geralmente, as regiões mais dinâmicas possuem maior vantagem competitiva, em função do seu perfil de especialização. As regiões mais especializadas tendem a auferir maiores ganhos de produtividade ao longo do tempo (SOUZA; SOUZA, 2004). Assim, sua relação custo/unidade produzida cai, permitindo à empresa uma melhora nas suas margens de lucro para competir via preços. Como a variável utilizada nessa análise é o valor da produção silvícola, a melhoria nos preços ou na quantidade produzida em função de uma maior disponibilidade de terras e produtividade tende a fortalecer o Efeito Competitivo.

\section{Resultados e discussões}

A tabela 1 apresenta os resultados das estimativas dos indicadores de deslocamento e de reestruturação da produção silvícola do Estado do Paraná nos períodos 2005 e 2016.

Tabela 1: Paraná: deslocamento e reestruturação da produção silvícola (2005/2016)

\begin{tabular}{lcc}
\hline Atividade & $\begin{array}{c}\text { Deslocamento regional } \\
(\mathrm{Idd})\end{array}$ & $\begin{array}{c}\text { Reestruturação regional } \\
\text { (Ireest) }\end{array}$ \\
\hline Carvão vegetal & 0,36474 & 0,0009 \\
Eucalipto folhas & 0,98020 & 0,0000 \\
Lenha & 0,24898 & 0,0742 \\
Madeira em tora & 0,09860 & 0,0279 \\
Madeira papel e celulose & 0,14344 & 0,0547 \\
Madeira outras finalidades & 0,14226 & 0,0826 \\
Resinas & 0,56579 & 0,0174
\end{tabular}

Fonte: resultados da pesquisa a partir de dados do Paraná (2020).

A tabela 2 apresenta os resultados do efeito competitivo da produção silvícola em atividades selecionadas nas microrregiões do Estado do Paraná. As microrregiões de Paranaguá, Maringá, Porecatu, Astorga, Apucarana e Florai não apresentaram efeito competitivo 
significativo (acima de $\mathrm{R} \$ 1$ milhão), tanto para ganhos quanto para perdas. Por isso, os dados de algumas microrregiões não foram apresentados na tabela 2.

Tabela 2 - Paraná: efeito competitivo da produção silvícola em atividades selecionadas (2005/2016) - Valores em $\mathrm{R} \$ 1.000,00$.

\begin{tabular}{|c|c|c|c|c|c|}
\hline Microrregiões & $\begin{array}{l}\text { Carvão } \\
\text { vegetal }\end{array}$ & Lenha & $\begin{array}{r}\text { Madeira } \\
\text { em tora }\end{array}$ & $\begin{array}{r}\text { Madeira papel } \\
\text { e celulose }\end{array}$ & $\begin{array}{r}\text { Madeira outras } \\
\text { finalidades }\end{array}$ \\
\hline Cerro Azul & 49.822 & 1.384 .643 & 68.679 & -32.323 & 97.723 \\
\hline Ivaiporã & 364.443 & 40.980 & -12.044 & -34.753 & 226.193 \\
\hline Wenceslau Braz & 6.130 & 907 & 28.054 & --- & 20.732 \\
\hline São Mateus do Sul & -358 & 38.196 & 63.277 & -3.538 & 251.140 \\
\hline União da Vitória & -171 & 26.945 & -35.580 & 225.582 & -39.932 \\
\hline Rio Negro & 1.600 & 1.072 & 35.599 & -9.122 & 40.432 \\
\hline Irati & -45 & 15.876 & 47.425 & 35.133 & 26.704 \\
\hline Prudentópolis & -31 & 6.707 & 17.479 & 8.287 & 11.025 \\
\hline Campo Mourão & & 39.358 & 24.443 & -2.295 & 19.961 \\
\hline Ibaiti & -405 & -4.273 & 58.236 & 73.153 & -249 \\
\hline Assaí & --- & -1.620 & -6.804 & -2.752 & -4.052 \\
\hline Capanema & -30 & 178 & 5.881 & --- & 4.999 \\
\hline Cascavel & --- & 64.864 & 20.831 & --- & 9.667 \\
\hline Cianorte & -223 & -7.330 & -34.878 & --- & -20.636 \\
\hline Cornélio Procópio & -72 & -1.576 & -360 & -2.346 & 832 \\
\hline Curitiba & -1.562 & -18.619 & 31.222 & -17.120 & 47.983 \\
\hline Faxinal & 2.112 & 163 & -2.654 & -1.174 & -1.486 \\
\hline Foz do Iguaçu & -55 & -397 & -7.895 & --- & -4.499 \\
\hline Francisco Beltrão & & 3.036 & 20.629 & --- & 16.576 \\
\hline Goioerê & -34 & 500 & -6.172 & --- & -3.663 \\
\hline Guarapuava & -3.565 & -16.356 & -148.412 & -82.030 & -63.114 \\
\hline Jacarezinho & -41 & 776 & 2.969 & --- & 2.730 \\
\hline Jaguariaíva & 39.649 & -79.687 & -29.829 & 129.436 & -76.892 \\
\hline Lapa & -246 & 401.791 & -22.084 & -18.015 & -2.866 \\
\hline Londrina & --- & -231 & 2.567 & -602 & 2.490 \\
\hline Palmas & -385 & -8.748 & -8.452 & -8.050 & 129 \\
\hline Paranavaí & -57 & 497 & 9.960 & --- & 8.099 \\
\hline Pitanga & --- & 124.787 & -1.476 & -1.307 & -75 \\
\hline Ponta Grossa & -187 & -3.345 & 22.263 & -6.175 & 56.020 \\
\hline Telêmaco Borba & -5.591 & -32.631 & -91.776 & 10.361 & -255.393 \\
\hline Toledo & -47 & 1.331 & -310 & --- & 681 \\
\hline Umuarama & 182 & 2.029 & -17.085 & --- & -9.973 \\
\hline
\end{tabular}

Fonte: Resultados da pesquisa a partir de dados do Paraná (2020).

Até 2016, no comparativo com outras regiões paranaenses de produção silvícola, o acréscimo competitivo da microrregião de Telêmaco Borba não foi muito significativo, pois só a variação da produção de lenha em Cerro Azul correspondeu a 202\%. As atividades de Eucalipto 
folhas e resinas não tiveram valores significativos, por isso não estão expostos na tabela 2. Ou seja, sua estrutura produtiva não apresentou crescimento competitivo diferenciado entre as microrregiões paranaenses, o que se percebeu pelo indicador de reestruturação (Tabela 1).

A partir dos resultados da estimativa do Indicador de deslocamento e reestruturação e da análise de dados de produção silvícola oriundos do Ipardes (2018), a distribuição inter-regional das atividades silvícolas no Estado do Paraná apresentou certas particularidades. A primeira delas está relacionada à alteração na participação de determinadas microrregiões, que foi brusca entre 2005 e 2016. Um exemplo é o caso da produção de carvão vegetal em Curitiba e Guarapuava, que caiu de $19,84 \%$ e $39,65 \%$ para 0,00\%, respectivamente. Enquanto essas microrregiões zeraram sua participação nessa atividade, Wenceslau Braz e Jaguariaíva avançaram de 0,22\% e $2,43 \%$ para $25,85 \%$ e $29,75 \%$, respectivamente. A produção de carvão vegetal se deslocou mais e mais para o Norte Pioneiro paranaense. A exceção ficou por conta de Umuarama que dobrou sua participação saindo de $8,55 \%$ para $16,56 \%$ no período. Mas foi um caso isolado no Noroeste paranaense. Por conta de um deslocamento, no qual nenhuma microrregião obteve ganhos significativos em termos de reestruturação produtiva, o indicador de deslocamento (Idd) do carvão vegetal ficou em terceiro no ranking, conforme resultados apresentados na tabela 1.

A segunda particularidade percebida com os resultados da pesquisa foi a tendência à concentração e especialização de algumas microrregiões. Por exemplo: enquanto a produção de carvão vegetal se desloca lentamente para o Norte Pioneiro, a produção de Eucalipto folhas se deslocou de forma significativa das microrregiões do Norte Pioneiro e Noroeste paranaense para a microrregião de Cascavel no Oeste paranaense. A microrregião de Cascavel praticamente concentrou a produção desse produto ao longo do período ficando altamente especializada, o que posicionou o resultado do Idd da produção de Eucalipto folhas $(0,98)$ como o mais significativo do período.

Da mesma maneira, a produção de madeira para papel e celulose se apresentou altamente especializada regionalmente no Paraná. Enquanto Ivaiporã perdeu participação na atividade, reduzindo de 11,76\% em 2005 para 0,19\% em 2016, Jaguariaíva dobrou sua participação saindo de 9,25\% para 18,01\%. Mesmo assim ficou em segundo no ranking, pois a microrregião de Telêmaco Borba ampliou sua participação nessa atividade de 41,42\% para 43,38\%, entre 2005 e 2016. No mesmo período, União da Vitória saiu de uma produção de 3,55\% para 9,91\% e Ibaiti de 1,29\% para 7,30\%. Com exceção de União da Vitória, as outras microrregiões são contiguas o que forma um cinturão produtivo na área de papel e celulose. 
Outra atividade que apresentou alta concentração foi a de produção de resinas nas microrregiões de Guarapuava, Jaguariaíva e Cerro Azul, que perdeu participação de 88,51\% para 33,66\% entre 2005 e 2016. Ou seja, a estrutura produtiva de Cerro Azul se diversificou dentro da cadeia produtiva silvícola, pois a microrregião ainda é significativa na produção de outros produtos de madeira. Quem emergiu nessa atividade produtiva foi Guarapuava e Campo Mourão, que avançaram de 0,00\% de participação em 2005 para 32,39\% e 15,16\%, respectivamente, em 2016. Ou seja, Guarapuava e Campo Mourão destinaram áreas para essa atividade produtiva, o que retirou participação de Cerro Azul na produção inter-regional e não necessariamente retraiu sua produção. Esses resultados colocaram a produção de resinas como a segunda com maior Idd no período.

No caso da mesorregião Centro-Sul do Paraná, na qual se localiza a microrregião de Guarapuava, Palmas, Pitanga e União da Vitória, alguns estudos foram efetuados para demonstrar a viabilidade da silvicultura e do extrativismo florestal, em especial com o uso da Araucária, em relação à produção agropecuária. A expansão dessas atividades nas propriedades rurais ainda depende da conciliação das florestas plantadas com a paisagem natural, a reconstrução da biodiversidade em áreas degradadas e o acesso a linhas de crédito, como o Pronaf-Florestal. Como discussões sobre a viabilidade da silvicultura no Centro-Sul ocorrem desde o final dos anos 1990, então o aumento da participação de Guarapuava no contexto da produção silvícola paranaense já é um reflexo de uma transição produtiva nas áreas rurais dessa região (SILVA; CLEMENTE, 2008).

A terceira particularidade na produção silvícola paranaense, apontada pelos resultados da pesquisa, foi sua tendência à dispersão regional de algumas atividades. As atividades mais diversas apresentaram maior indicador de reestruturação, que está ligado diretamente à especialização produtiva. Ou seja, essas atividades fortaleceram a diversificação das microrregiões dentro da cadeia produtiva da silvicultura. Por exemplo: ao contrário do carvão vegetal e da produção de Eucalipto folhas, a produção de lenha e madeira para outras finalidades é bem mais dispersa no território paranaense. Todas as microrregiões têm alguma produção nessas atividades, sendo que na produção de lenha o Oeste e o Sudoeste paranaense tem uma participação mais significativa, mas abaixo de 10\%. Em ambas as mesorregiões, as microrregiões de Francisco Beltrão, Toledo e Cascavel fecharam 2016 com uma participação de 8,50\%, 9,36\% e 10,00\% respectivamente. Essas microrregiões possuem plantas agroindustriais que demandam lenha e outras fontes energéticas para alimentar suas caldeiras. Já a madeira para outras 
finalidades, as microrregiões que detinham a maior participação em 2005 perderam posição em 2016, enquanto as microrregiões de Cerro Azul e Curitiba avançaram no ranking. No caso da microrregião de Curitiba, o uso de madeira para a produção de carvão vegetal migrou 100\% para outras finalidades e, também, madeira em tora.

A produção de madeira em tora é mais significativa em Telêmaco Borba e Jaguariaíva, que são microrregiões contiguas. Apesar da participação dessas microrregiões ter caído de $23,71 \%$ e $14,73 \%$ para 19,68\% e 13,43\% entre 2005 e 2016, respectivamente, ambas continuam liderando a participação inter-regional do Paraná. A terceira no ranking é União da Vitoria, com uma participação 12,06\% em 2016 ante 13,62\% em 2005. A queda mais significativa foi de Guarapuava, pois sua produção de madeira em tora se retraiu de $14,71 \%$ para 8,32\% no período. A retração de Guarapuava reforçou a produção contigua desse produto para Cerro Azul, que expandiu de 5,34\% para 7,64\% a sua produção. Guarapuava também ampliou sua participação na produção de resinas, o que implica em alguns casos evitar o corte da madeira enquanto ela tem volume de geração de látex e derivados. As outras microrregiões do Paraná mantiveram sua produção estável ou tiveram um pequeno aumento de participação demonstrando que a produção de madeira em tora está se dispersando ao longo do território e reforçando sua presença em Cerro Azul, Jaguariaíva e Telêmaco Borba.

Outra microrregião que apresentou dados significativos para madeira em tora e madeira para outras finalidades foi Ponta Grossa. Nesse caso, a microrregião avançou na produção de chapas e laminados. Com a presença de uma dezena de empresas na produção de chapas e laminados, se cogitou a criação de um arranjo produtivo local nessa atividade. Porém, o fortalecimento da indústria de base florestal na microrregião de Ponta Grossa dependerá dos seguintes elementos: estímulos para a ampliação das florestas plantadas, melhoria na qualificação e capacitação da mão-de-obra, novas linhas de crédito para a modernização das plantas existentes e uma política tributária diferenciada para o setor. Ou seja, o potencial produtivo para a expansão dos negócios na área silvícola na microrregião de Ponta Grossa dependerá de um conjunto de medidas que exigirá uma forte mobilização das lideranças do setor (SOUZA; PORCILE, 2008). 


\subsection{O efeito competitivo e a deslocalização da produção silvícola no Paraná.}

O valor bruto da produção da silvicultura paranaense cresceu a uma taxa média de $1,74 \%$ ao ano no período de 2005 a 2016. Essa taxa varia muito quando se observa as atividades de forma desagregada. No período, a produção de lenha foi a mais significativa, com uma taxa de crescimento de 5,55\% a.a., seguida da produção de madeira para papel e celulose, com taxa média de 2,52\% a.a. A menor taxa de crescimento foi da produção de resinas e Eucalipto folhas com 0,11 e 0,19\%, respectivamente. As outras atividades silvícolas tiveram variação superior a $1 \%$ e menor que $2 \%$ ao ano.

No conjunto da economia brasileira ocorreu a diminuição do uso de lenha como fonte de energia, mas no Paraná o uso de lenha no período estudado apresentou alta. Dentre as explicações para a manutenção do uso da lenha no Paraná, destacam-se: a produção e o uso de carvão mineral como combustível apresentou uma queda $-13 \%$ ao final de 2016 , demonstrando um possível efeito substituição; o Paraná não apresenta plantas de gás natural, diferente de outros estados federados, o que lhe deixa altamente dependente da estrutura e da infraestrutura de gasodutos, em especial do Gasbol. Além disso, o gasoduto existente no estado não atende áreas interioranas com plantas agroindustriais, como as mesorregiões Oeste, Sudoeste e Noroeste do Paraná. Outro elemento que reforça o uso da lenha nas empresas agroindustriais é o aumento do uso desse material no setor de alimentos e bebidas. Em 2006, entre as fontes energéticas, a participação da lenha era de 8,9\%, mas em 2016 essa participação chegou a 9,1\% no conjunto das indústrias brasileiras de alimentos e bebidas (BRASIL, 2020).

A variação conjunta do valor bruto da produção mascara os aspectos regionais, que demonstram a competitividade e o crescimento regionalizado da produção. No período de 2005 a 2016, Telêmaco Borba teve um crescimento total da produção silvícola na ordem de 14,86\%, o que correspondeu a um acréscimo direto de produção na ordem $\mathrm{R} \$ 42$ milhões capitaneado pela produção de madeira para celulose e papel. Isso sem contar os impactos indiretos no emprego e na renda regional, por conta dos efeitos multiplicadores gerados pela industrialização mais intensiva da madeira. Cabe lembrar que no município de Ortigueira (PR), pertencente à microrregião de Telêmaco Borba, uma nova usina da Klabin, para o processamento de madeira para celulose e papel entrou em operação em 2016. Isso significa que o valor adicionado bruto dessa microrregião deverá ter um aumento significativo a partir de 2017. 
A microrregião de Cerro Azul, que apresentou o maior efeito competitivo no Paraná, migrou o uso da sua produção silvícola da madeira para papel e celulose para lenha, carvão vegetal, madeira para outras finalidades e madeira em tora. Nesse caso, Cerro Azul está agregando menos valor a sua matéria prima ou exportando para que o valor seja agregado na indústria de papel e celulose em outras microrregiões. $O$ aspecto positivo disso é a integração intrarregional entre as cadeias produtivas do entorno de Cerro Azul, mas com o aspecto negativo de gerar valor adicionado em atividades menos intensivas em tecnologia. Os municípios que mais ganharam competitividade em agregação de valor na atividade de processamento de madeira para papel e celulose foi União da Vitoria, com um valor estimado em $\mathrm{R} \$ 225$ milhões no período; Jaguariaíva com R\$129 milhões. Na sequência apresentam-se se Ibaiti, Irati e Telêmaco Borba. A microrregião de Guarapuava foi a que mais perdeu competitividade nessa atividade, na ordem de menos $\mathrm{R} \$ 82$ milhões de produção que não foi acrescida, frente à adição de outras microrregiões.

Maxir e Masullo (2017), estudando a inserção do Brasil no comercio internacional de produtos da cadeia florestal chamaram a atenção que o país ainda tem muita dependência da importação de papel. Ou seja, a expansão da cadeia produtiva ligada à estrutura de celulose e papel só vem a fortalecer o comercio externo brasileiro e pode ajudar no equilíbrio do balanço de pagamentos brasileiro. Porém, Raiher (2011) chama a atenção que qualquer expansão produtiva em termos de crescimento das atividades deve ser acompanhada de melhorias nos indicadores de capita humano, senão o desenvolvimento socioeconômico regional não se sustentará a longo-prazo. Isso denota que o desenvolvimento regional das regiões de exploração e transformação silvícola demanda políticas públicas e ações em prol das populações locais concomitante ao fortalecimento da cadeia produtiva de base florestal.

\section{Considerações finais}

Esse artigo analisou o deslocamento da produção silvícola e seu padrão de localização entre as microrregiões do Paraná no Brasil. O procedimento metodológico consistiu na estimativa dos indicadores de localização e o efeito competitivo a partir de dados do valor da produção silvícola regional do Estado do Paraná. A periodização utilizada foi o comparativo entre 2005 e 2016, haja vista a disponibilidade de informações. 
Os resultados demonstraram o deslocamento progressivo de um conjunto de atividades silvícolas para áreas do Norte Pioneiro, Ponta Grossa, Sudeste e Centro Sul do Paraná, em especifico nas microrregiões de Cerro Azul, Telêmaco Borba, Ibaiti, Irati Jaguariaíva, Rio Negro, São Mateus do Sul, Prudentópolis e União da Vitoria. Essas microrregiões avançaram num conjunto de atividades, em especial a produção de madeira para celulose e papel, madeira em toras e madeira para outras finalidades.

Diferente das microrregiões supracitadas, as microrregiões de Toledo, Campo Mourão, Cascavel, Francisco Beltrão avançaram na produção de lenha ou carvão vegetal, em grande parte para atender seu complexo agroindustrial de proteína vegetal e animal. Isso demonstra a necessidade de investimentos em infraestrutura para o transporte de gás natural. Da mesma maneira, investimentos na geração de biogás, a partir de dejetos de animais e resíduos domésticos, aparentam ser uma alternativa viável para a preservação das áreas florestais e para a diminuição da emissão de gases que causam efeito estufa.

Assim, os dados demonstraram um perfil de relocalização da produção e transformação silvícola que tem beneficiado as microrregiões mais pobres do Paraná em termos de participação no Produto Interno Bruto estadual. Em geral, o relevo, a fertilidade do solo e os benefícios fiscais concedidos para empreendimentos que processam madeira têm contribuído para a atratividade da atividade silvícola em microrregiões nas quais empreendimentos agropecuários tem baixa rentabilidade. Geograficamente, enquanto a produção de proteína animal e vegetal se estabelece nas mesorregiões Oeste, Sudoeste e Norte Central do Estado, as microrregiões da porção leste do território paranaense se posicionam no beneficiamento e transformação de madeira. Nesse sentido, novas pesquisas são necessárias para discutir os impactos sociais, o adensamento das cadeias produtivas e a geração de emprego formal ao longo do tempo nas microrregiões que ganharam ou perderam competitividade na atividade silvícola.

\section{Referências}

ALMEIDA Á.S.; MACDONELL M. Resinagem de Pinus no Paraná. Revista Paranaense de Desenvolvimento, № 57, p. 75-104, 1976.

ALVES, L. Indicadores de localização, especialização e estruturação Regional. In: PIACENTI, A.C.; FERRERA DE LIMA, J. (org.). Análise regional: Metodologias e Indicadores. Curitiba: Camões, 2012, p. 33-49.

BERGER, R.; ALMEIDA, Á.S. Compensados de madeira. Revista Paranaense de

Desenvolvimento, no 32, p. 21-68, 1972. 
CARAVIERI, A. M.; BRENE, P. R.; SESSO FILHO, U. A.; CAMPOS, A. C.; RODRIGUES, R. L. APL madeireiro e mobiliário de São Bento do Sul e de Arapongas: uma análise comparativa utilizando o índice Rasmussen-Hirschman. Revista Informe GEPEC, vol. 18, № 01, p. 101-118, 2014.

COSTA, J.S. Compêndio de Economia Regional. Lisboa: APDR, 2002.

BRASIL. Empresa de Pesquisa Energética - EPE. Balanço energético nacional. 2020.. Disponível em: <http://www.epe.gov.br/pt/publicacoes-dados-abertos/publicacoes/balanco-energeticonacional-ben>. Acesso em 05 junho 2020.

FERRERA DE LIMA, J. Méthode d'analyse regionale: indicateurs de localisation, de structuration et de changement spatial. Saguenay, Canadá : UQAC/GRIR, 2006.

FISCHER, A. O fomento na indústria de base florestal. Revista Informe GEPEC, vol. 13, no 02, p. 6-19, 2009.

GUIMARÃES, D. Madeira e derivados. Revista Paranaense de Desenvolvimento, no 40, p. 0928, 1974.

HADDAD, P.R. Economia regional: teoria e métodos de análise. Fortaleza: BNB/ETENE, 1989.

LOURENÇO, G. Complexo industrial da madeira: alternativa de desenvolvimento para o Paraná. Revista Paranaense de Desenvolvimento, , Curitiba: Ipardes, no 57, p. 75-104, 1979.

MAXIR, H.S.; MASULLO, LS. A inserção do Brasil no comércio internacional de produtos da cadeia florestal. Revista Árvore, Viçosa: UFV, v.41, no 03, p. 01-12, 2017.

NOJIMA, D. Crescimento e reestruturação industrial do Paraná 1985/2000. Revista Paranaense de Desenvolvimento, no 103, p. 23-43, 2002.

PARANÁ. Instituto Paranaense de Desenvolvimento Econômico e Social - Ipardes. Dados diversos do BDE. 2020. Disponível em: <www.ipardes.pr.gov.br>. Acesso em: 20 novembro 2020.

RAIHER, A. P. Os Determinantes da localização industrial por nível tecnológico no Paraná: ênfase no capital humano. Revista Informe GEPEC, vol. 15, no 02, p. 18-35, 2011.

SANTOS, E. C.; SILVA, E. P. Suprimento de biomassa lenhosa para cadeia produtiva da indústria oleira no Estado do Amazonas - Brasil. Revista Informe GEPEC, vol. 17, no 01, p.132-149, 2013.

SILVA, M.; CLEMENTE, A. Contribuição potencial das florestas de Araucária para a sustentabilidade da agricultura familiar do Centro-Sul do Paraná. Revista Paranaense de Desenvolvimento, no 114, p. 111-131, 2008.

SOUZA, C. C. G.; ALVES, L. R. A especialização e a reestruturação produtiva das atividades econômicas entre as mesorregiões do Brasil entre 2000 a 2009. Revista Informe GEPEC, vol. 157, no especial, p. 145-161, 2011.

SOUZA, N.; PORCILE J.G. Arranjos produtivos locais: o caso de chapas e laminados de Ponta Grossa. Revista Paranaense de Desenvolvimento, №. 114, p. 53-85, 2008.

SOUZA, N.J; SOUZA; R.B. Dinâmica estrutural-diferencial da região Metropolitana de Porto Alegre, 1990-2000. Revista de Economia, vol. 30, no 02, p.121-144, 2004.

ZANIOLO, A. Perspectivas para a economia florestal. Revista Paranaense de Desenvolvimento, no 18, p. 29-48, 1970. 